\title{
Dopplerometric Assessment of Cerebral Hemodynamics in Ischemic Stroke
}

\section{Rizvan Ya Abdullaiev ${ }^{1 *}$, Faina I Kulikova ${ }^{2}$, Vladimir M Baibakov ${ }^{2}$, Alla G Kyrychenko ${ }^{2}$, Irina A Zayats ${ }^{2}$ and Mikhail V Solomenko²}

${ }^{1}$ Kharkiv Medical Academy of Postgraduate Education, Ukraine

${ }^{2}$ Dnipro Medical Institution of Traditional and Alternative Medicine, Ukraine

*Corresponding Author: Rizvan Yagubovich Abdullaiev, Department of Ultrasound Diagnostics, Kharkov Medical Academy of Postgraduate Education, Ukraine.

Received: July 08, 2019; Published: July 25, 2019

DOI: 10.31080/ASNE.2019.02.0087

\begin{abstract}
Background: As you know, cardiovascular diseases are a common cause of death and disability, among them a special place is occupied by stroke.

Objective: to determine the quantitative parameters of blood flow of the main brain vessels in patients with left hemispheric ischemic stroke (HIS). Methods: transcranial dopplerography (TD) of the middle cerebral artery (MCA) and middle cerebral vein (MCV), the Rosenthal's vein, the Galena's vein and Straight sinus (SS) was performed in 89 patients with HIS. The comparative group (CG) was organized from 52 patients without cardiovascular diseases. The maximum systolic velocity (Vs), the end diastolic velocity (Vd), the resistance index (RI) in MCA, and the Vs of the main brain veins were determined.

Results: Sistolic blood flow velocity in the mid-cerebral artery in $85.4 \%$ of patients was below $70 \mathrm{~cm} / \mathrm{s}$ and averaged, $54.9 \pm 7.1 \mathrm{~cm} / \mathrm{s}$. In $9.2 \%$ of cases, the size of the affected area in the left hemisphere did not exceed $1 \mathrm{~cm}$ according to the results of tomography, and in $90.8 \%$ of cases it ranged from $1 \mathrm{~cm}$ to $2 \mathrm{~cm}$ According to the results of TD, MSA stenosis was detected in 78 (87.6\%) cases, which was confirmed by MRI angiography. Among the patient with the Hemispheric ischemic stroke the Rosenthal's vena was visualized in $81(91,0 \%)$ cases, the Galen's vena - in $83(93,3 \%)$ cases, the median cerebral vein (MCV) - in $75(84,3 \%)$ and the Straight sinus - in $79(88,9 \%)$ cases, respectively. In a patients of the comparative group, visualization of this veins was successful in 42 (80.8\%), 47 (90.4\%), 31 (59.6\%) and 32 (61.5\%) cases, respectively. In a patients with HIS, all the main cerebral veins were visualized significantly ( $\mathrm{P}<0.05$ and $\mathrm{P}<0.001$ ) more often than in the CG (with the exception of the Galen vein). In a patient with HIS Vs in the deep median cerebral vein was $25.3+3.6 \mathrm{~cm} / \mathrm{s}$; in the basal vein of the brain $-24.9+2.6 \mathrm{~cm} / \mathrm{s}$; in the large vein of the brain $-26.3+2.1 \mathrm{~cm} / \mathrm{s}$; in the direct sinus, $32.1 \pm 2.6 \mathrm{~cm} / \mathrm{s}$, respectively.

Conclusion: Stenosis of the middle cerebral artery, a decrease in systolic blood flow velocity less than $70 \mathrm{~cm} / \mathrm{s}$, an increase in resistance index more than 0.70 and in the pulsation index more than 1.35 is a frequent finding in ischemic stroke. The correspondence between the severity of the stroke and the value of the systolic blood flow velocity in the cerebral veins was revealed. Good visualization of the main cerebral veins is due to the increase in blood flow velocity in them.
\end{abstract}

Keywords: Transcranial Dopplerography; Hemispheric Ischemic Stroke; Cerebral Hemodynamics

\section{Abbreviation}

TD: Transcranial Dopplerography; HIS: Hemispheric Ischemic Stroke; CH: Cerebral Hemodynamics.

\section{Introduction}

It is known that about $20 \%$ of cardiac output through the carotid arteries enters the brain. The degree of cerebral stenosis de- 
termines the volume of blood flow to the brain. At the same time, the severity of clinical symptoms depends not only on the degree of arterial hemodynamic impairment, but also on the state venous blood flow from the brain. Previous studies have shown that the clinical symptoms of ischemic stroke are determined not only by the volume of blood flowing through the arterial vessels, but also by the outflow of blood through the venous vessels from the brain $[1,2]$. Developed by Singer O.C., et al. (2005) the clinical scale provides the accuracy of determining the occlusion of the cerebral artery about 85\% [3]. Research results Allen LM., et al. (2012) using CT and MR angiography made it possible to determine the area of arterial occlusion, the mechanisms of stroke development and the prevalence of the affected area [4]. In recent years, transcranial dopplerography has been used to determine cerebral hemodynamics in various pathological conditions $[5,6]$.

Objective to determine the quantitative parameters of blood flow of the main brain vessels in patients with left hemispheric ischemic stroke.

\section{Patients and Methods}

Transcranial dopplerography (TD) of the middle cerebral artery (MCA) and middle cerebral vein (MCV), the Rosenthal's vein, the Galena's vein and Straight sinus (SS) was performed in 89 patients with hemispheric ischemic stroke (HIS). The age of the subjects varied within 43-78 years, there were 41 men (46.1\%), women 48 (53.9\%). The comparative group (CG) was organized from 52 patients without cardiovascular diseases. The following quantitative blood flow parameters were determined: systolic and diastolic velocity (Vs, Vd), mean systolic velocity (TAMX), resistant and pulsation indices (RI and Pi) in MCA and Vs of the main cerebral veins. Statistical analysis consisted in unvaried comparisons of unpaired groups, performed with the Fisher's exact test for categorical data. The significance level, two-tailed, was set at $\leq 0.05$ for moderately significant, at $\leq 0.01$ for significant and at $\leq 0.001$ for highly significant.

\section{Results}

Sistolic blood flow velocity in the mid-cerebral artery in $85.4 \%$ of patients was below $70 \mathrm{~cm} / \mathrm{s}$ and averaged, $54.9 \pm 7.1 \mathrm{~cm} / \mathrm{s}$. In $9.2 \%$ of cases, the size of the affected area in the left hemisphere did not exceed $1 \mathrm{~cm}$ according to the results of tomography, and in $90.8 \%$ of cases it ranged from $1 \mathrm{~cm}$ to $2 \mathrm{~cm}$ According to the results of TD, MSA stenosis was detected in 78 (87.6\%) cases, which was confirmed by MRI angiography. TCD in 37 (41.6\%) cases showed moderate or severe stenosis of first segment of the left MCA, which was confirmed in 35 cases with MRI angiography (Figure 1,2). On the $3^{\text {rd }}$ week from the beginning of the stroke, repeated transcranial dopplerography was performed. Under dynamic observation, fatal outcome was noted in three cases, serious complications in 34 patients.

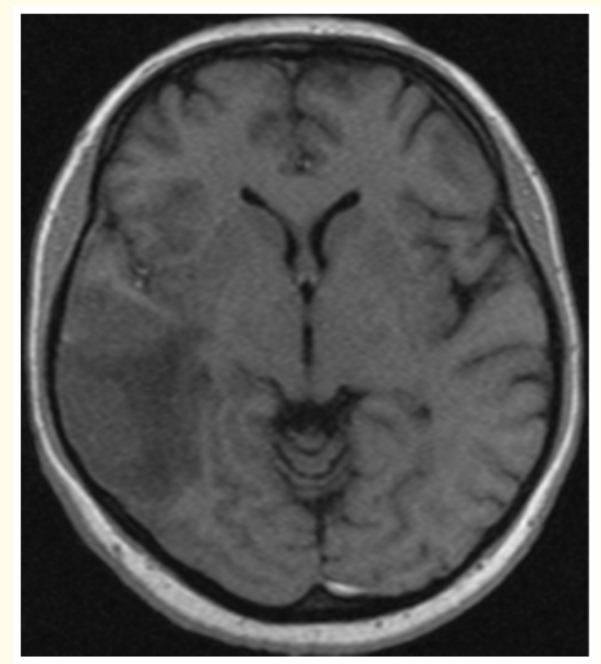

Figure 1: MRI with ischemic stroke in the left MCR basin (left hypodence zone).

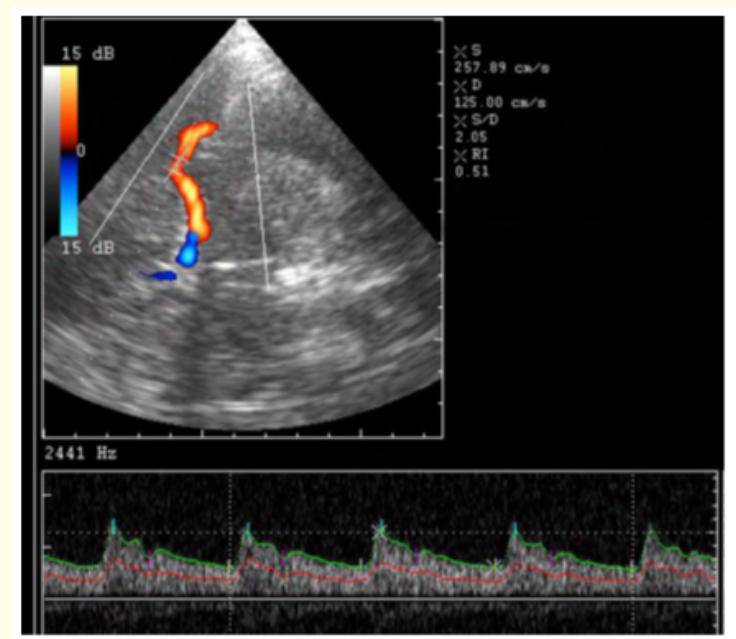

Figure 2: Ttanscranial dopplerography of a patient with left hemispheric ischemic stroke. Stenosis of first segment of left middle cerebral artery. Vs - $257 \mathrm{~cm} / \mathrm{c}$. 
Comparison of hemodynamic parameters of patients with an unfavorable course between the first day and the third week of stroke did not reveal any significant differences At the same time, the data of patients with stroke significantly $(\mathrm{P}<0,001)$ differed from those of the comparative group (Table 1).

\begin{tabular}{|l|c|c|c|}
\hline $\begin{array}{l}\text { The hemody- } \\
\text { namic parameters } \\
\text { of blood flow in } \\
\text { second segment } \\
\text { of MCA }\end{array}$ & $\begin{array}{c}\text { HIS } \\
\text { unfavorable } \\
\text { outcome } \\
\text { (n=36) }\end{array}$ & $\begin{array}{c}\text { HIS } \\
\text { favorable } \\
\text { outcome } \\
\text { (n=53) }\end{array}$ & CG (n =52) \\
\hline Vs, cm/s & $\begin{array}{c}49.3 \pm 6.1 \\
\mathrm{P}<0,05\end{array}$ & $87,5 \pm 5,9$ & $104,5 \pm 4,9$ \\
\hline Vd, cm/sec & $\begin{array}{c}6.9 \pm 1.7 \\
\mathrm{P}<0,01\end{array}$ & $31,6 \pm 2,3$ & $48,7 \pm 2,3$ \\
\hline TAMX, cm/sec & $\begin{array}{c}30,5 \pm 3,6 \\
\mathrm{P}<0,01\end{array}$ & $58,9 \pm 6,7$ & $64,9 \pm 5,8$ \\
\hline RI & $\begin{array}{c}0.86+0.07 \\
\mathrm{P}<0,05\end{array}$ & $0,64 \pm 0,05$ & $0,53 \pm 0,04$ \\
\hline PI & $\begin{array}{c}1,39 \pm 0,12 \\
\mathrm{P}<0,01\end{array}$ & $0,98 \pm 0,07$ & $0,86 \pm 0,05$ \\
\hline
\end{tabular}

Table 1: Hemodynamic parameters in second segments of MCA in patients with hemispheric ischemic stroke unfavorable outcome on the affected side and in a comparative group.

Among the patient with the Hemispheric ischemic stroke the Rosenthal's vena was visualized in $81(91,0 \%)$ cases, the Galen's vena - in $83(93,3 \%)$ cases, the median cerebral vein (MCV) - in $75(84,3 \%)$ and the Straight sinus - in $79(88,9 \%)$ cases, respectively. In a patients of the comparative group, visualization of this veins was successful in 42 (80.8\%), 47 (90.4\%), 31 (59.6\%) and $32(61.5 \%)$ cases, respectively. In a patients with HIS, all the main cerebral veins were visualized significantly $(\mathrm{P}<0.05$ and $\mathrm{P}<0.001)$ more often than in the CG (with the exception of the Galens vena) (Table 2). In a patient with HIS Vs in the deep median cerebral vein was $25.3+3.6 \mathrm{~cm} / \mathrm{s}$; in the basal vein of the brain $-24.9+2.6 \mathrm{~cm} / \mathrm{s}$; in the large vein of the brain $-26.3+2.1 \mathrm{~cm} / \mathrm{s}$; in the direct sinus, 32.1 $\pm 2.6 \mathrm{~cm} / \mathrm{s}$, respectively (Table 3 ).
80

\begin{tabular}{|l|c|c|}
\hline $\begin{array}{l}\text { The frequency of visual- } \\
\text { ization of the main brain } \\
\text { veins, \% }\end{array}$ & HIS (n =89) & CG (n=52) \\
\hline Galen's vena & $83(93,3 \pm 2,7)$ & $47(90,4 \pm 4,1)$ \\
\hline Rosenthal's vein & $\begin{array}{c}81(91,0 \pm 3,0) \\
P<0,05\end{array}$ & $42(80,8 \pm 5,4$ \\
\hline Median cerebral vein & $\begin{array}{c}75(84,3 \pm 3,8) \\
P 1-3<0,001\end{array}$ & $31(59,6 \pm 6,8)$ \\
\hline Straight sinus & $79(88,9 \pm 3,5)$ & $32(61,5 \pm 6,7)$ \\
\hline
\end{tabular}

Table 2: The frequency of visualization of the main brain veins in patients with hemispheric ischemic stroke and comparative group.

\begin{tabular}{|l|c|c|}
\hline $\begin{array}{l}\text { The systolic blood } \\
\text { flow velocity, cm/s }\end{array}$ & HIS (n =89) & CG (n =52) \\
\hline Galen's vena & $\begin{array}{c}26,3 \pm 2,1 \\
\mathrm{P}<0,05\end{array}$ & $19,5 \pm 1,9$ \\
\hline Rosenthal's vein & $24,9 \pm 2,6$ & $15,8 \pm 2,3$ \\
\hline Median cerebral & $\mathrm{P}<0,01$ & \\
vein & $25,3+3,6$ & $13,7 \pm 1,8$ \\
\hline Straight sinus & $\mathrm{P}<0,01$ & \\
\hline
\end{tabular}

Table 3: The maximum blood flow velocity in the large brain veins in a patients with hemispheric ischemic stroke and comparative group.

\section{Discussion}

In earlier studies, the role of Doppler sonography in assessing the patency of cerebral vessels in patients with acute stroke was shown. Trained medical staff can perform an ultrasound examination of the brain's blood vessels within minutes [7-9]. A high correlation was found between the extracranial venous blood flow and the degree of cerebral venous insufficiency in patients with multiple sclerosis [10]. 
Cerebral perfusion and venous outflow resistance, factors, that determine cerebral venous pressure. This affects the speed of the venous blood flow and contributes to the development of cerebral edema in patients with ischemic stroke. In ischemic stroke, there is an inverse relationship between arterial and venous cerebral blood flow - the first decreases more often, the second increases. We have established a positive relationship between the systolic blood flow velocity in the main veins of the brain and the severity of ischemic stroke.

\section{Conclusion}

Stenosis of the middle cerebral artery, a decrease in systolic blood flow velocity less than $70 \mathrm{~cm} / \mathrm{s}$, an increase in resistance index more than 0.70 and in the pulsation index more than 1.35 is a frequent finding in ischemic stroke. The correspondence between the severity of the stroke and the value of the systolic blood flow velocity in the cerebral veins was revealed. Good visualization of the main cerebral veins is due to the increase in blood flow velocity in them.

\section{Acknowledgment}

Special thanks to the participants for their patience and kindness.

\section{Conflict of Interest}

The authors declare no conflicts of interest.

\section{Bibliography}

1. Cebral JR., et al. "Blood-flow in the Circle of Willis from magnetic resonance data". Journal of Engineering Mathematics 47.3-4 (2003): 369-386.

2. Valdez-Jasso D., et al. "Viscoelastic mapping of the arterial ovine system using a Kelvin model" (2007).

3. Singer OC., et al. "A simple 3-item stroke scale: comparison with the National Institutes of Health Stroke Scale and prediction of middle cerebral artery occlusion". Stroke 36.4 (2005): 773-776.

4. Allen LM., et al. "Sequence specific MR imaging findings that are useful in dating ischemic stroke". Radiographics 32.5 (2012): 1285-1297.

5. Navarro JC., et al. "The accuracy of transcranial Doppler in the diagnosis of middle cerebral artery stenosis". Cerebrovascular Diseases 23 (2007): 325-330.
6. Tsivgoulis G., et al. "Validation of transcranial Doppler with computed tomography angiography in acute cerebral ischemia". Stroke 38.4 (2007): 1245-1249.

7. Schlachetzki F., et al. "Transcranial ultrasound from diagnosis to early stroke treatment-Part 2: Prehospital neurosonography in patients with acute stroke-The Regensburg Stroke Mobile Project". Cerebrovascular Diseases 33.3 (2012): 262-271.

8. Hedna VS., et al. "Hemispheric differences in ischemic stroke: is left-hemisphere stroke more common?". Journal of Clinical Neurology 9.2 (2013): 97-102.

9. Akif Topcuoglu M. "Transcranial Doppler ultrasound in neurovascular diseases: diagnostic and therapeutic aspects". Journal of Neurochemistry 123 (2012): 39-51.

10. Simka M., et al. "Extracranial Doppler sonographic criteria of chronic cerebrospinal venous insufficiency in the patients with multiple sclerosis". International Angiology 29.2 (2010): 109114.

Volume 2 Issue 8 August 2019

(C) All rights are reserved by Rizvan Ya Abdullaiev., et al. 